\title{
VARIABLE VENTRICULAR COMPLEXES IN HEART BLOCK, AND THEIR RELATION TO BILATERAL BUNDLE BRANCH BLOCK
}

\author{
BY \\ C. W. CURTIS BAIN \\ From the Cardiographic Department, Harrogate General Hospital \\ Received November 29, 1940
}

Variable ventricular complexes in heart block have been recorded by a number of writers since they were first described by Mathewson (1913). King (1934) found them in five out of thirty-six cases with the double lesion of complete heart block and bundle branch block. Cohn (1913) noted both left and right bundle branch block and transitional complexes in a case passing from partial to complete A-V block, and he suggested that the changes might be due either to depression of conductivity in both branches alternately or else to a wandering pacemaker. Gilchrist and Cohn (1928) thought the latter explanation the more likely, and attributed the transitional complexes to the almost synchronous discharge of impulses from centres in each ventricle. Similar views have been expressed by Willius (1924), by Coelho (1932), and by Scherf and Schott (1932). On the other hand, Mathewson considered that in his case the impulse was being conducted alternately by each branch.

The diagnosis of bilateral bundle branch block was first made by Cohn and Lewis (1912) in a patient who had suffered from many Stokes-Adams attacks and was found at autopsy to have both branches divided from each other and from the main stem; the QRS was widened to $\cdot 2$ sec., which they thought might be characteristic of the condition. Faulkner (1932) also gives bilateral bundle block as an explanation of a wide QRS without axis deviation. However, in a similar case of separation of the branches from each other and from the main stem reported by Don, Grant, and Camp (1932) variable ventricular complexes occurred without gross widening of the QRS and they attributed the changes to a shift in the pacemaker from one ventricle to the other.

The suggestion that lesions are more likely to be found in the bundle branches than in the main stem, when variable ventricular complexes accompany A-V block derives from the experimental work of Wilson and Hermann (1921). When both branches of the bundle had been cut in dogs, they found that standstill of the ventricles only lasted a few minutes, after which centres in each ventricle took over. The resulting complexes might be of either branch block 
type or might be normal. Transitional complexes they ascribed to the interplay of two centres, one on each side of the heart, which were not discharging their impulses synchronously. When one branch started to recover, incomplete A-V block occurred for a time combined with bundle branch block that was permanent. Interest in this conception of bilateral bundle branch block was revived by Yater, Cornell, and Clayton (1936), who made histological studies in three cases of heart block with varying ventricular complexes; in one they found that both branches were destroyed, while in the other two there was extensive disease in each of the branches; in all three the main stem was relatively healthy: they concluded that in all cases of heart block associated with variable ventricular complexes the pacemakers are situated in the ventricles below lesions in the branches, and that the leadership of the pacemaker changes from one side to the other.

Four such cases have been recently observed. Two were usually associated with complete A-V block; in two the A-V block varied. When dealing with ventricular centres a difficulty arises, since a rhythm originating in a bundle branch is designated by a term that indicates disease in the other branch, which may not be present. To avoid confusion, the classical terminology of bundle branch block adopted by the Criteria Committee of the New York Heart Association (1939) has been followed in describing the cases, except that a QRS of $\cdot 12 \mathrm{sec}$. has been deemed sufficiently long to justify a diagnosis of bundle branch block. But in the discussion curves will usually be described according to the branch through which conduction takes place.

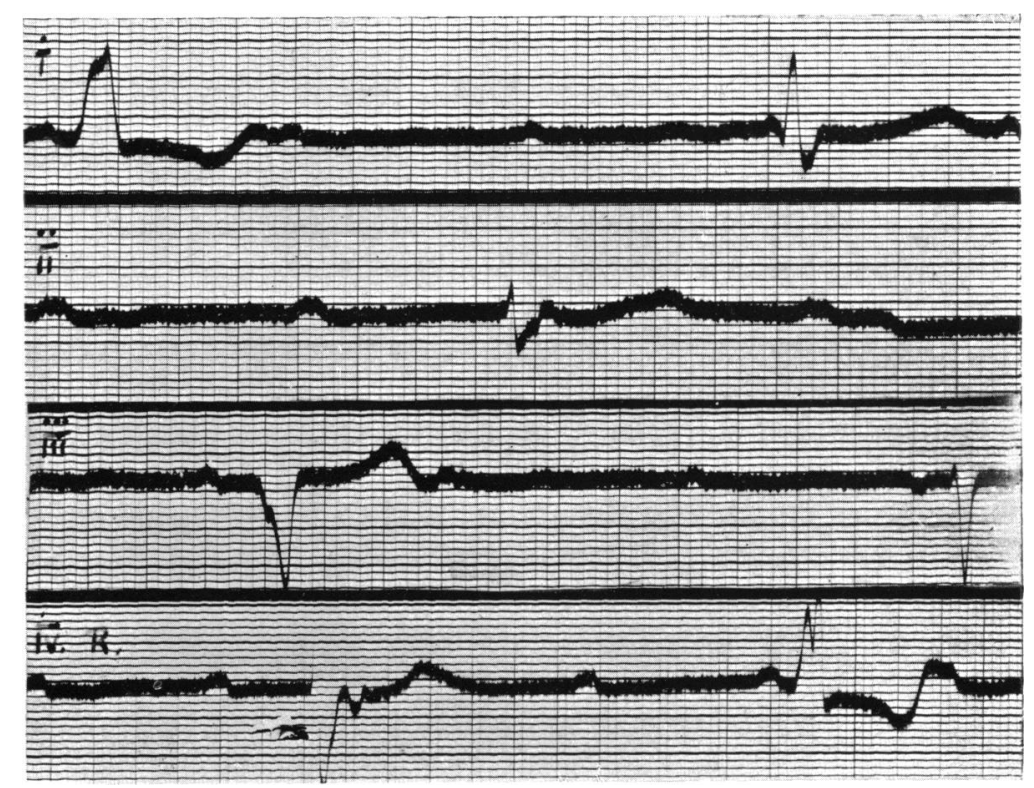

Fig. 1.-Case 1. 14,7,39. Complete A-V block with a ventricular rate of 26. Alternate left (discordant type, QRS $\cdot 15$ sec.) and right (type $B, Q R S \cdot 12$ sec.) branch block. Note inverted $\mathbf{P}$ deforming S-T interval in first complex of lead IVR. (See p. 78.) 


\section{Notes of THE First CASE}

A man of 67 had noticed dyspnœa on exertion for two months. His pulse rate was 32. A musical systolic murmur was audible at the apex, and a harsh systolic murmur at the aortic base. The heart was a little enlarged to the left; the ascending aorta was prominent; the blood pressure was 190/110; and the Wasserman reaction was negative. He was taken into hospital in July 1939

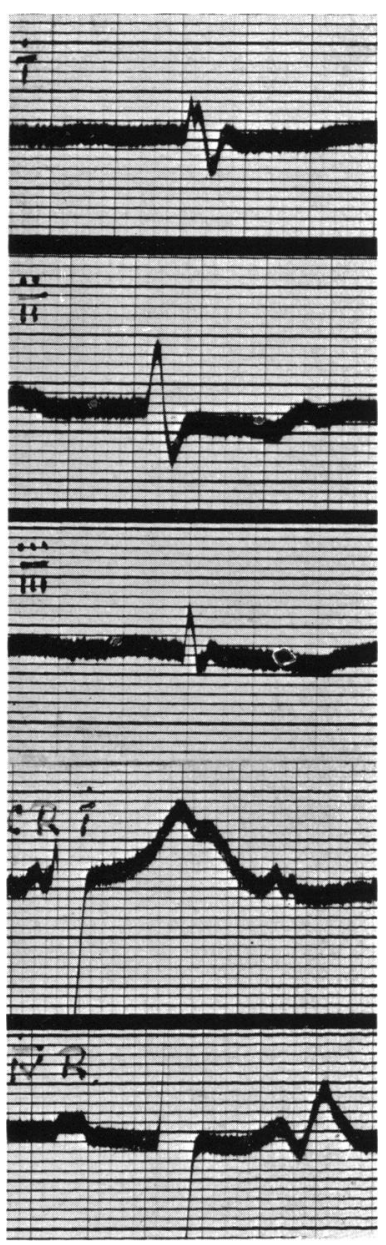

FIG. 2.-Case 1. 25,7,39. Complete A-V block. Low voltage curve of right-sided type (QRS · 11 sec.).

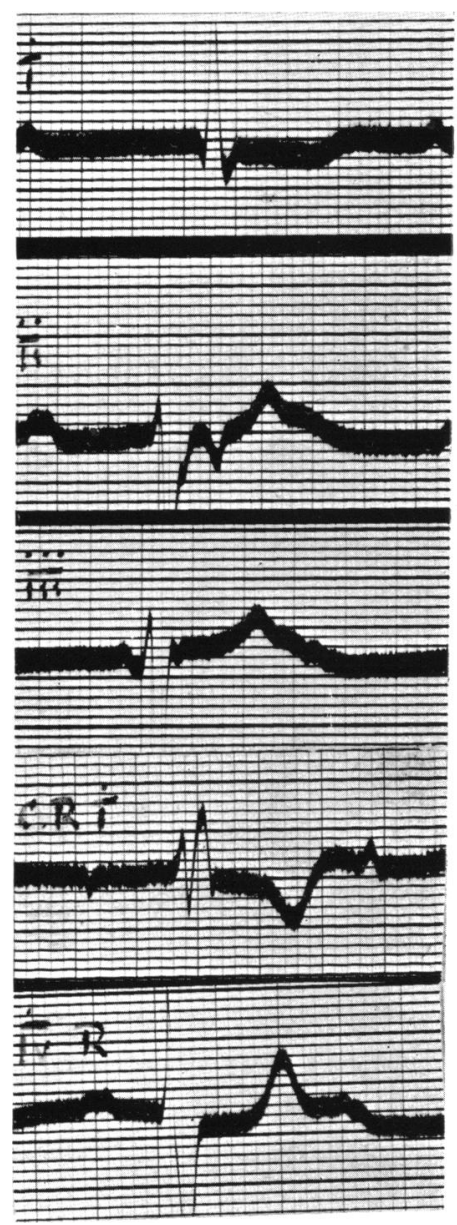

Fig. 3.-Case 1. 1,8,39. Complete A-V block. Right branch block (type B, QRS · $12 \mathrm{sec}$.). Note inverted $P$ deforming $S-T$ interval in lead II.

for observation. Ephedrine had no effect upon the ventricular rate, and he now maintains fair health upon moderate doses of digitalis. He has never had Stokes-Adams attacks.

Numerous electrocardiograms taken during his stay in hospital and since his discharge all showed complete A-V block. The $\mathrm{P}$ waves were not very 
regular and were sometimes flattened. On six occasions early inverted $P$ waves deformed the $\mathrm{S}-\mathrm{T}$ period, indicating retrograde conduction from ventricle to auricle. They all followed the $\mathrm{R}$ wave by $\cdot 16$ to $\cdot 18 \mathrm{sec}$., and occurred when the interval between the preceding $P$ and the $R$ was from $\cdot 50$ to $\cdot 58 \mathrm{sec}$. (Figs. 1 and 3).

The ventricular complexes varied. Fig. 1 shows complexes of left and right branch block. The left branch block complexes are of the discordant type and they have a QRS of $\cdot 15 \mathrm{sec}$. The right branch block complexes are of type B and have a QRS of $\cdot 12 \mathrm{sec}$. The ventricular rate is 26 and regular. No transitional complexes are present.

After rest the left branch block complexes disappeared, and their place was taken by a low voltage curve of right-sided type with a QRS of $\cdot 11 \mathrm{sec}$. at a rate of about 30 (Fig. 2), which has alternated with the right branch block (Fig. 3) since.

Injection of $\cdot 5$ c.c. adrenaline at a time when the low voltage curve was present led to an acceleration of eight beats (from 30 to 38). No premature beats were seen, but the following changes were observed: After three minutes the curve returned to right branch block, type B; after eight minutes two complexes. with a normal QRS of $\cdot 07 \mathrm{sec}$. occurred (Fig. 4): at ten minutes

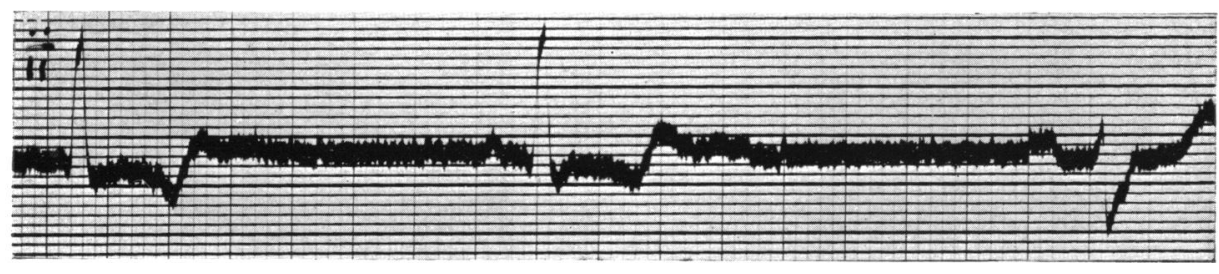

FIG. 4.-Case 1. 25,7,39. Showing two complexes with QRS of $\cdot 07 \mathrm{sec}$., 8 minutes after injection of $\cdot 5$ c.c. of adrenaline.

the low voltage complexes were again present, but from thirteen minutes onward the curve returned to right branch block, type B.

Summary.-In a man with complete heart block in the forward direction but with evidence of retrograde conduction at times from ventricle to auricle, the following changes in the ventricular complexes were observed.

1. Left bundle branch block (QRS, $\cdot 15)$.

2. Right bundle branch block of type $B(Q R S, \cdot 12)$.

3. Low voltage curve of right sided type $(\mathrm{QRS}, \cdot 11)$.

4. Normal QRS (·07) after adrenaline.

\section{Notes of THE SECONd CASE}

A man of 67 was admitted to the Harrogate General Hospital in June 1939. He had been conscious of dyspnœa on exertion since an attack of influenza two months previously. He had experienced three attacks of unconsciousness during the previous two days.

The pulse rate was 32 . There were no murmurs, but auricular sounds 
were audible at the apex. The heart was considerably enlarged to left and right, the cardio-thoracic ratio being $16 \mathrm{~cm} . / 28 \mathrm{~cm}$. The blood pressure was 200/70. The Wasserman reaction was negative.

He was allowed to get up, but he then complained of dizziness, and the pulse rate was found to have fallen to 26 . He was given ephedrine, gr. ii daily, and the pulse rate subsequently fluctuated from 32 to 36 . He was discharged in fair health, but later Stokes-Adams attacks recurred and he died in one in May 1940.

Most of the electrocardiograms showed complete A-V block ; incomplete (2: 1) A-V block occurring only at the end of, and for a short time after, his stay in hospital. On six occasions, when complete A-V block was present, early inverted $\mathbf{P}$ waves deformed the $\mathrm{S}-\mathrm{T}$ period, indicating retrograde conduction from ventricle to auricle. They all followed the $R$ wave by $\cdot 16$ sec., and occurred when the interval between the preceding $P$ and the $R$ was from $\cdot 42$ to .50 sec. (Figs. 5, 6, and 13).

Fig. 5, taken on admission, shows complete A-V block at a rate of 37 and

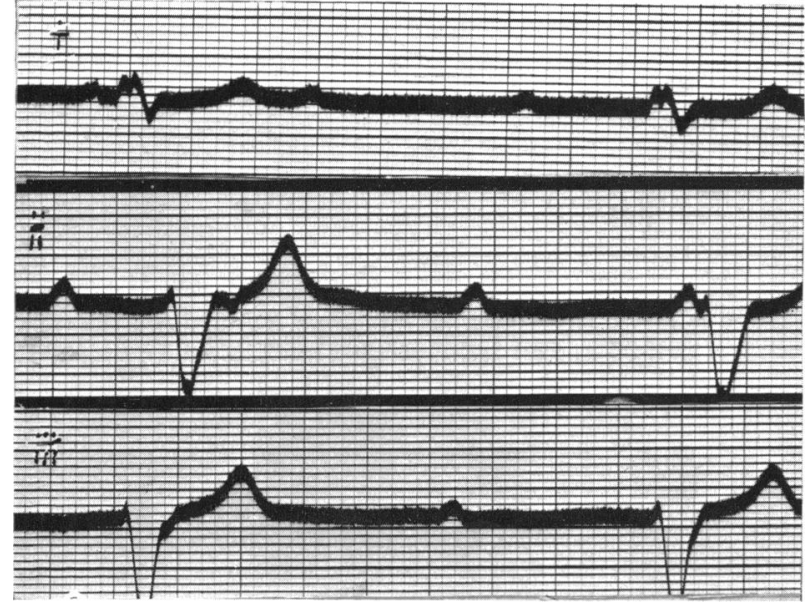

Fig. 5.

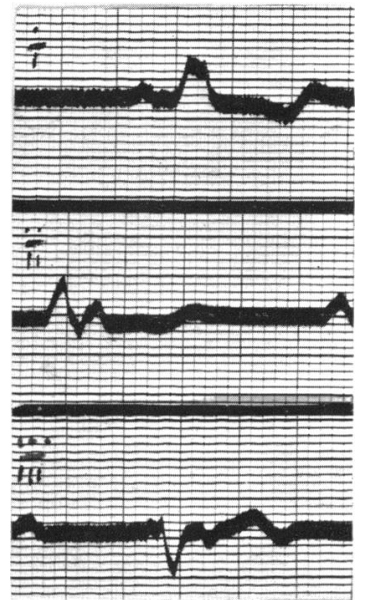

Fig. 6.

Fig. 5.-Case 2. 16,6,39. Complete A-V block. A typical right branch block (QRS, $\cdot 14$ sec.). Inverted $\mathbf{P}$ wave deforms $\mathbf{S}-\mathrm{T}$ interval of first complex in lead II.

Fig. 6.-Case 2. 22,6,39. Complete A-V block. Left branch block (QRS, $\cdot 12 \mathrm{sec}$.). Inverted $\mathbf{P}$ wave deforms S-T interval in lead III.

a bundle branch block with a QRS of 14 sec., which, though somewhat atypical, has been interpreted as a right branch block in view of the form of the chest leads recorded later (see Fig. 17). Fig. 6, which was taken after the fall in rate had been noted, shows a left branch block of the discordant type, (QRS, -12) at a rate of 29. For the next week the left branch block persisted, with rates varying from 27 to 32 . Adrenaline $\cdot 5$ c.c. was then given subcutaneously. This had no effect upon the ventricular rate, but after seven minutes a right branch block complex appeared, and after eleven minutes the curve changed to a type A right branch block (QRS, 14) at a rate of 27 in lead I and of 33 in lead III (Fig. 7). 
Three days later the A-V heart block began to lift, and the left branch block complexes now followed $P$ waves with a P-R interval of $\cdot 24 \mathrm{sec}$. At the same time right branch block complexes returned, being still associated with complete A-V block (see Fig. 17 on p. 84). Four days later incomplete (2:1) A-V block became established, both with left (Fig. 8) and right (Fig. 9, leads II and

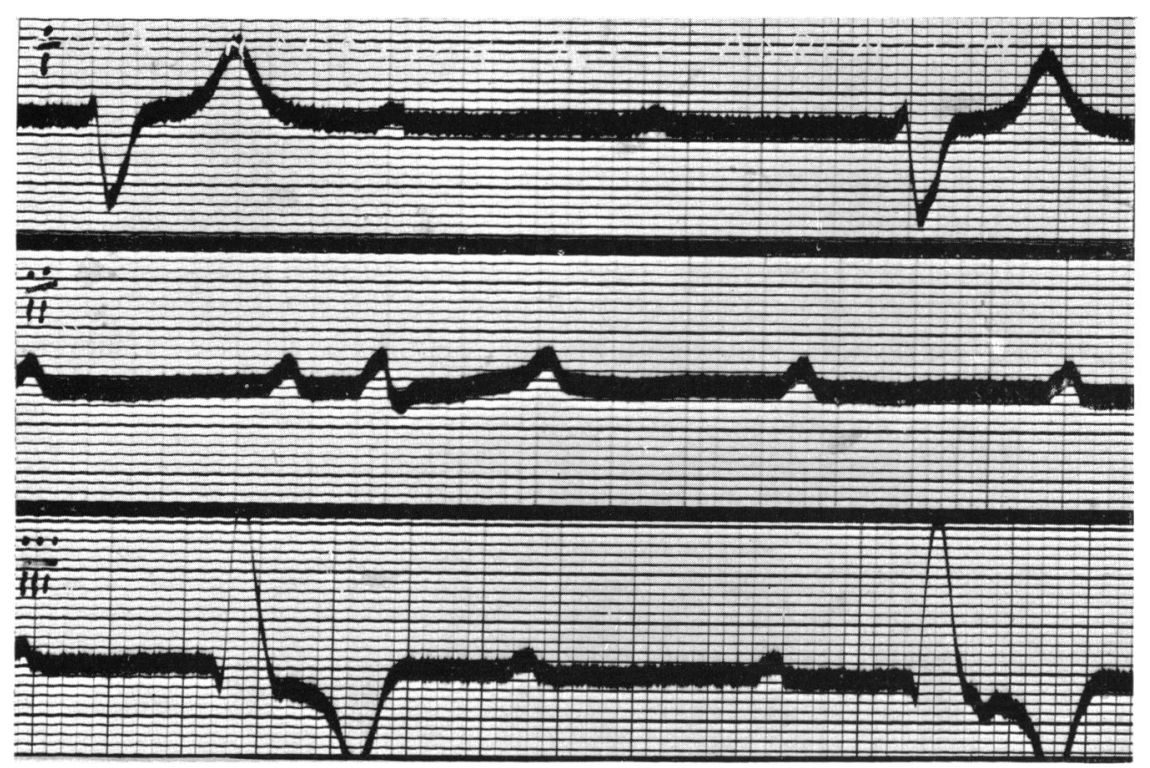

FIG. 7.-Case 2. 28,6,39. Eleven minutes after injection of $\cdot 5$ c.c. adrenaline. Complete A-V block (V. rate 27 in lead I and 33 in lead III). Right branch block (type A, QRS $\cdot 14 \mathrm{sec}$.).

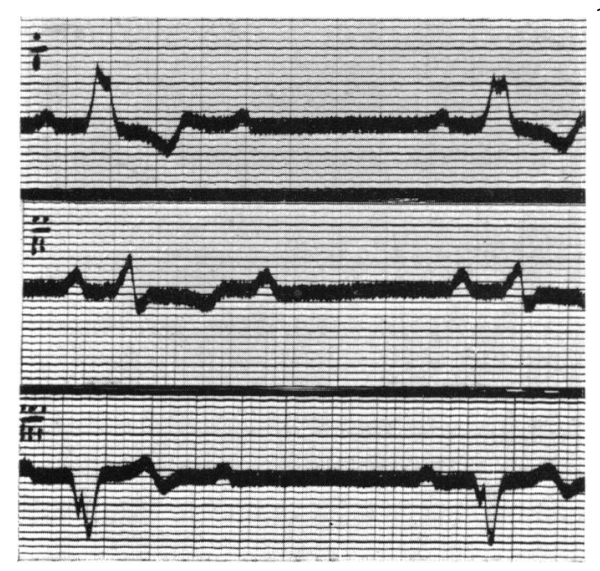

FIG. 8.

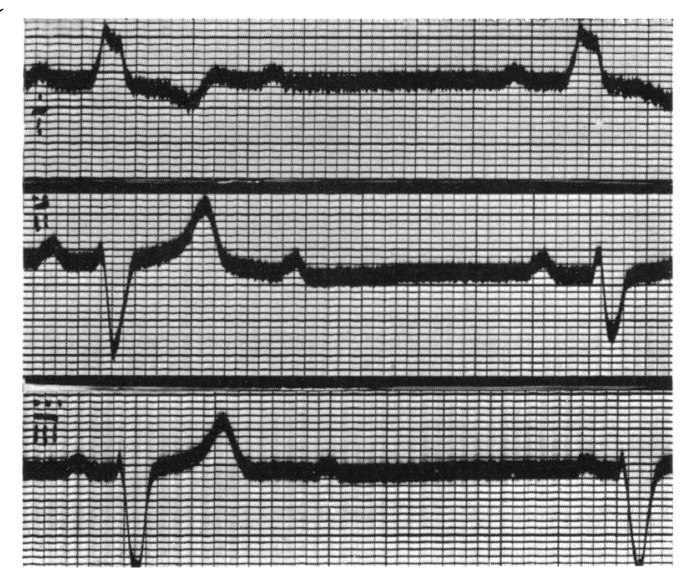

Fig. 9.

Fig. 8.-Case 2. 6,7,39. Incomplete (2:1) A-V block and left branch block (QRS, $\cdot 14 \mathrm{sec}$.).

Fig. 9.-Case 2. 6,7,39. Incomplete $(2: 1) \mathrm{A}-\mathrm{V}$ block with left branch block in lead I and right branch block in leads II and III. There is some variability in the QRS of the complexes in lead II, and of the P-R intervals in lead III. 
III) branch block, though there is some variability in the P-R intervals of the right branch block complexes. Incomplete (2:1) A-V block (with left branch block) persisted for two months, and lead II in Fig. 10 contains a run of three beats of 1:1 rhythm, the middle beat being a right branch block complex.

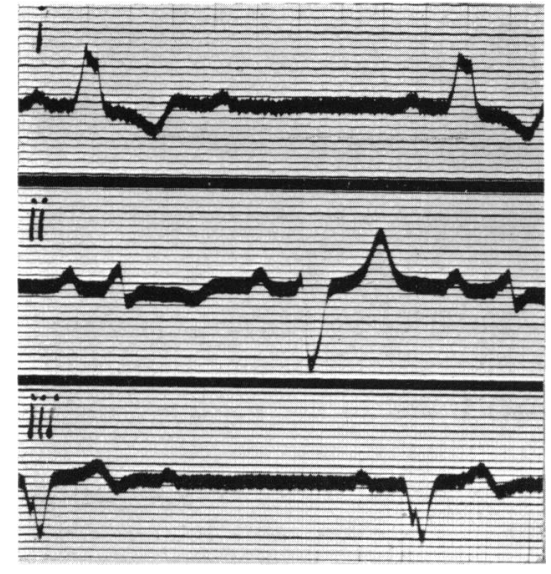

FIG. 10.

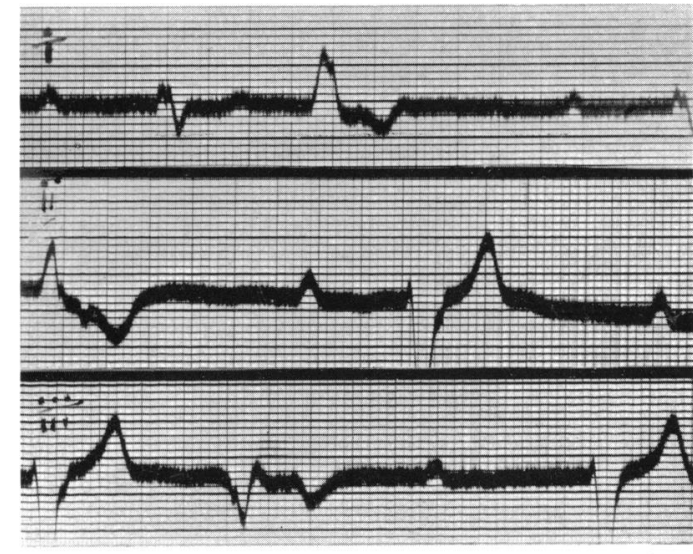

FIG 11.

FIG. 10.-Case 2. 28,7,39. Left branch block with incomplete $(2: 1) \mathrm{A}-\mathrm{V}$ block. In lead II a run of three beats of $1: 1$ rhythm occurs, the middle complex being one of right branch block.

Fig. 11.-Case 2. 22,9,39. Complete A-V block. Right branch block. Right ventricular premature contractions. An inverted $\mathbf{P}$ deforms the S-T period in the premature beat in lead II.

In September 1939 complete A-V block returned with right branch block, and early beats were seen arising from the right ventricle somewhat dissimilar in form from the left branch block complexes previously observed (Fig. 11). An inverted $\mathrm{P}$ deforms the $\mathrm{S}-\mathrm{T}$ period in the early beat in lead II and again in Fig. 13. Later, a transition from left to right branch block was recorded (Fig. 12), and a change from right to left branch block was obtained ten minutes

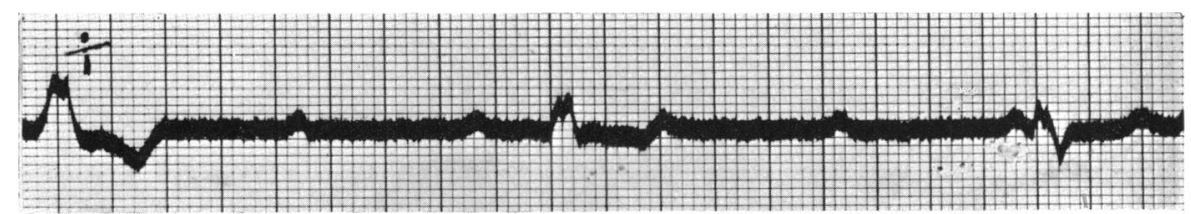

Fig. 12.-Case 2. 13,10,39. Complete A-V block. Transition from left to right branch block.

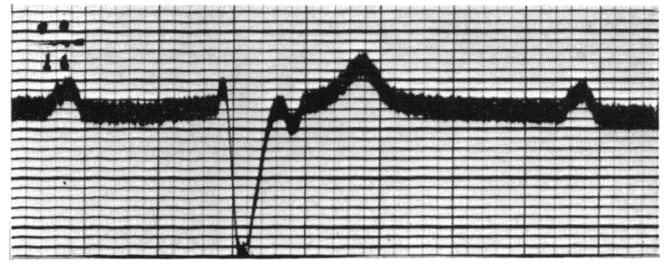

FIG. 13.-Case 2. 19,2,40. Lead II. Complete A-V block. Right branch block. An early and inverted $\mathbf{P}$ deforms the $\mathbf{S}-\mathbf{T}$ period. 
after the subcutaneous injection of atropine, gr. $1 / 30$, associated on this occasion with an increase in the rate from 31 to 35 .

Summary.-A man who died from Stokes-Adams disease had A-V heart block, usually complete in the forward direction, but with evidence of retrograde conduction at times from ventricle to auricle. The following changes in the ventricular complexes were observed.

1. Right branch block, atypical (QRS, ·14).

2. Left branch block (QRS, $\cdot 12-\cdot 14)$.

3. Right branch block of type A (QRS, -14) after adrenaline.

\section{Notes OF THE THIRd CASE}

A man of 59 was seen with Dr. Kerr Pringle in October 1937. In 1935 he had developed pernicious anæmia but the blood had been restored to normal. Three weeks previously he noticed a fullness in his neck and became conscious of the beating of his heart, the rate of which was found to be 30 . Since then he had been kept in bed.

The heart was not enlarged. There were no murmurs. The blood pressure was 160/110. Cardiograms showed a mixture of complete and incomplete (2:1) A-V block. He was admitted to hospital next day, when it was found that incomplete $(2: 1)$ A-V block only was present. Normal rhythm was restored, both by atropine and adrenaline, and was maintained during his stay in hospital with ephedrine. Subsequently he reverted to $2: 1 \mathrm{~A}-\mathrm{V}$ block, but a spontaneous return to normal rhythm took place seven months later and was maintained for a year. In July 1939 complete A-V block returned with a pulse rate of 20. Ten days later he experienced a succession of Stokes-Adams attacks, in one of which he died.

Fig. 14 shows that complete A-V block was associated with left hranch block

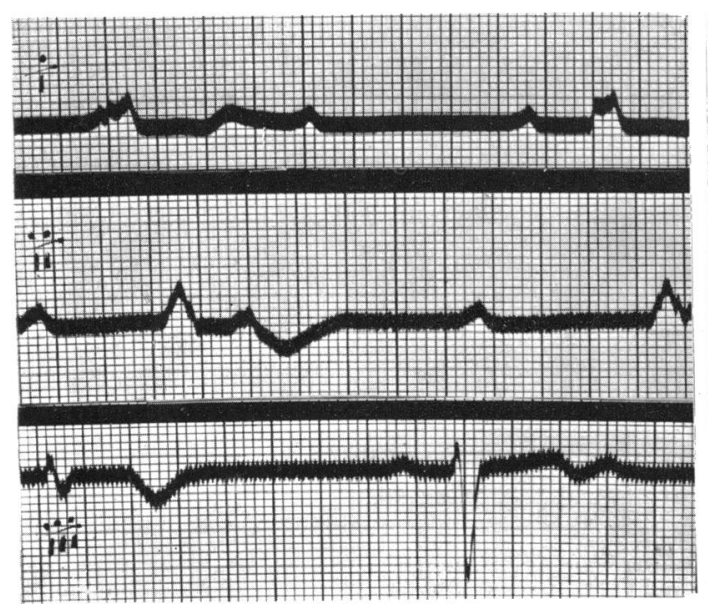

A

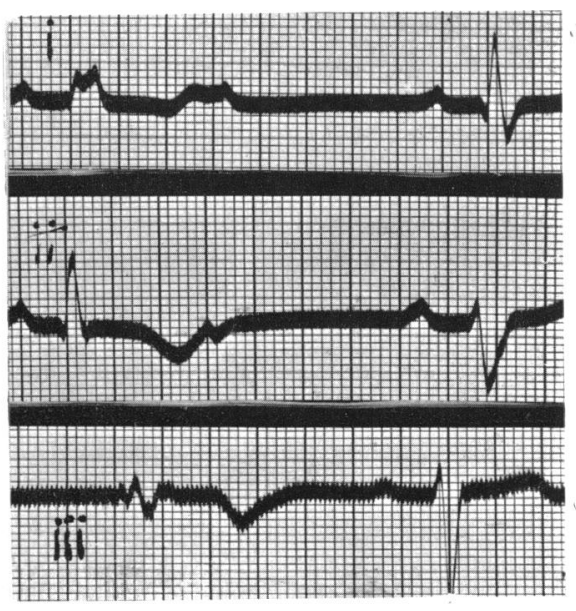

B

FIG. 14.-Case 3. 19,10,37. (A) and (B) Left branch block (concordant type, QRS 14 sec.) associated with complete A-V block at a rate of 30 . Also right branch block (type B. $\mathrm{QRS} \cdot 15 \mathrm{sec}$.) associated with incomplete A-V block (P-R $\cdot 28 \mathrm{sec}$.). The first complex in lead II in (B) is transitional and has a QRS of $\cdot 10 \mathrm{sec}$. 
of the concordant type $(\mathrm{QRS}, 14)$ at a rate of 30 , while right branch block, type $B$ complexes $(Q R S, \cdot 15)$ followed $P$ waves with a $P-R$ interval of $\cdot 28 \mathrm{sec}$. Their rate (from 33 to 44 ) is faster than that of the left branch block. In Fig. 14B the first complex in lead II (QRS, $\cdot 10$, sec.) is transitional. On the following day atropine, gr. 1/30, was given subcutaneously, and Fig. 15

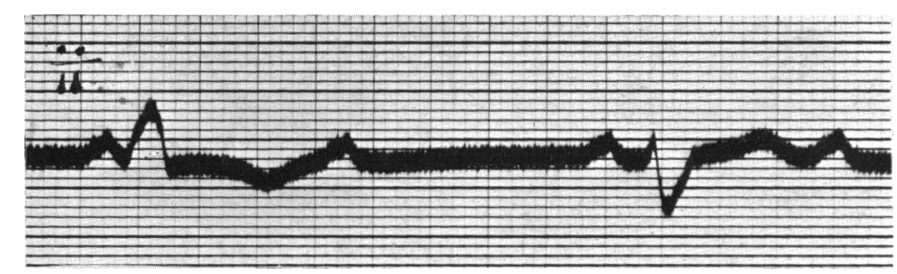

FIG. 15.-Case 3. 21,10,37. After injection of atropine, gr. 1/30. An early beat arises in the right ventricle 5 minutes before restoration of normal rhythm.

shows an early beat from the right ventricle which occurred five minutes before the restoration of normal rhythm. Next day adrenaline $(1$ c.c.) restored normal rhythm in five minutes, but subsequently induced premature beats from both ventricles (Fig. 16). Six months later, and a fortnight before the spontaneous

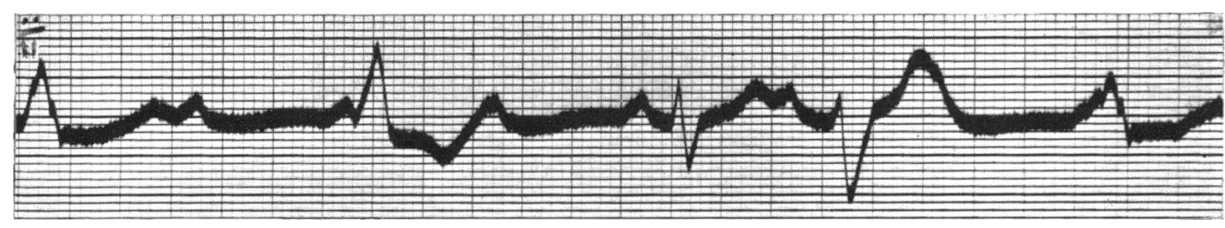

FIG. 16.-Case 3. 22,10,37. Premature beats from both ventricles after injection of 1 c.c. of adrenaline.

resumption of normal rhythm, early beats from the right ventricle occurred again (Fig. 18 on p. 84) and a transitional complex is seen at the end of lead III.

On July 9, 1939, he noticed his heart was acting slowly and his pulse rate was found to be 20 . On July 18 he had six Stokes-Adams attacks. When seen on July 19 the pulse was 20 , but the apex rate was faster, since there were beats which were not being transmitted to the wrist. While being attached to the cardiograph he had a Stokes-Adams attack. When the apex impulse returned, the rate was 50 and irregular. Fig. 19, taken a few minutes later, shows a return to the left branch block (concordant type) at a regular rate of 44 . The QRS is still $\cdot 14$ sec., but T is now flat in lead II and upright in lead III. The complexes resemble the premature beats from the right ventricle induced by adrenaline rather than the idio-ventricular rhythm of the first record, or the early beats that occurred spontaneously. The Q-T interval is prolonged to $\cdot 72 \mathrm{sec}$., compared with $\cdot 60 \mathrm{sec}$. during the initial phase and $\cdot 44 \mathrm{sec}$. when normal rhythm was present.

Summary.-In a man who died from Stokes-Adams disease complete A-V block was associated with left branch block of the concordant type (QRS of -14), while incomplete $(2: 1)$ A-V block and normal $(1: 1)$ rhythm were associated 


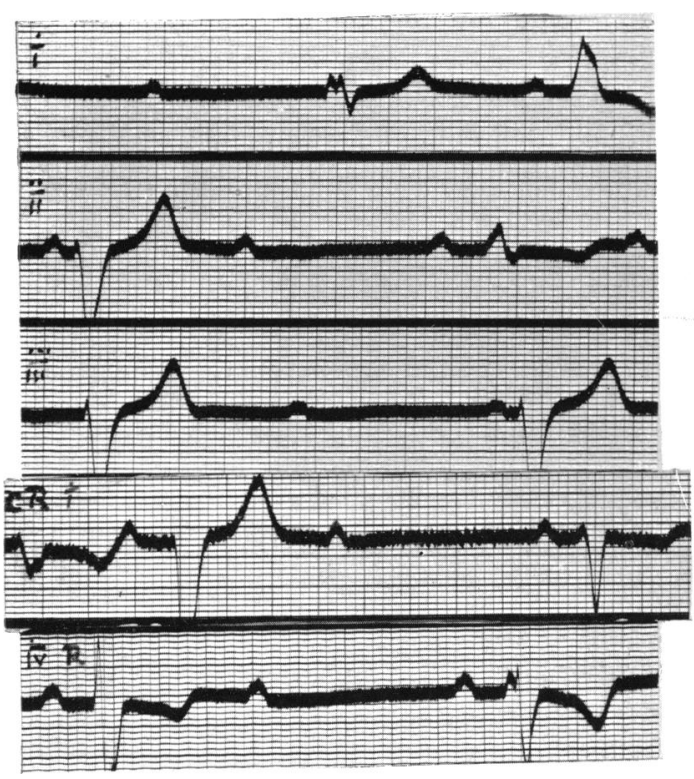

FIG. 17.

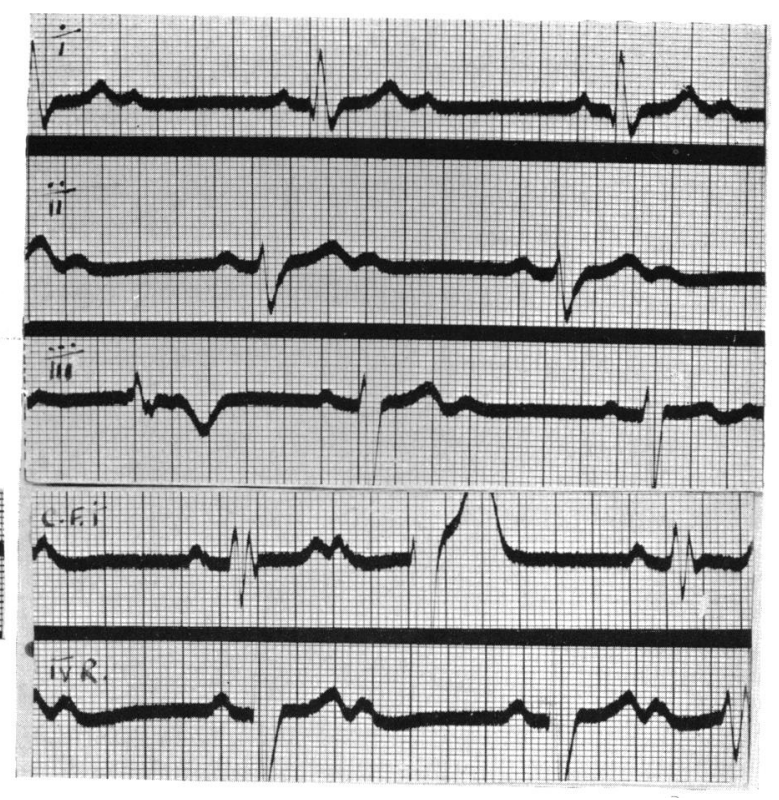

Fig. 18.

FIG. 17.-Case 2. 1,7,39. Alternating right and left branch block in leads I, II, CRI, and IVR. In lead III both complexes are right branch block. The third complex in CRI is transitional. Right branch block is associated with complete A-V block. Left branch block complexes follow $P$ waves with a $P-R$ interval of $\cdot 24$ sec.

Fig. 18.-Case 3. 22,5,38. Incomplete (2:1) A-V block Right branch block (type B) Early beats from right ventricle similar to the left branch block complexes of first record seen in leads III and CFI and IVR. The last complex in lead III is transitional.

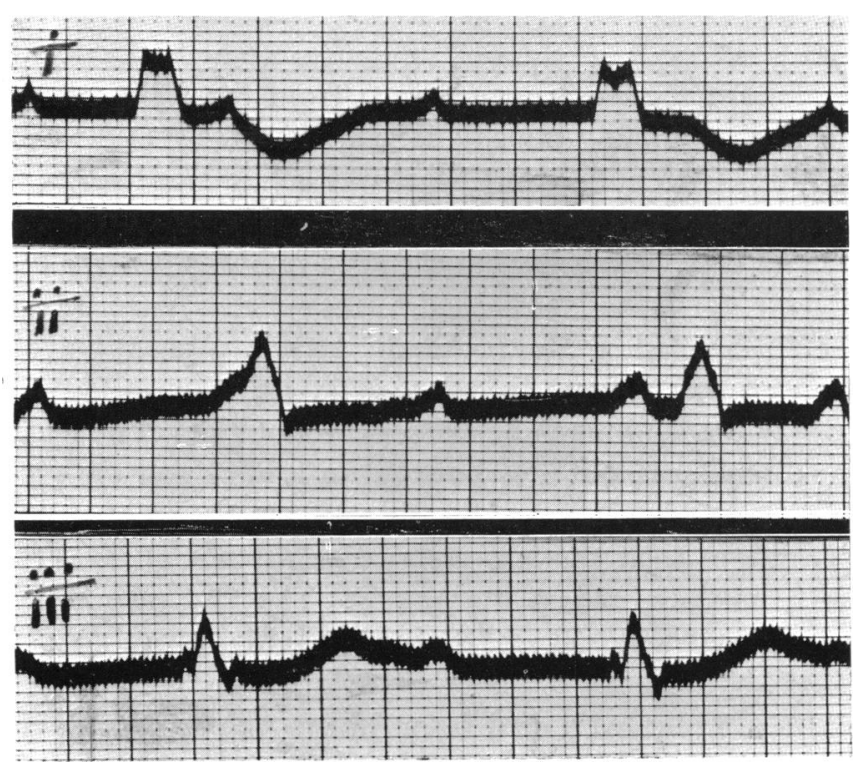

FIG. 19.-Case 3. 19,7,39. Left branch block (concordant type, QRS $\cdot 14 \mathrm{sec}$.). $T_{2}$ flat. $\mathrm{T}_{3}$ upright. $\mathrm{Q}-\mathrm{T}$ interval is $\cdot 72 \mathrm{sec}$. 
with right branch block of type $\mathrm{B}(\mathrm{QRS}, \cdot 15)$. A transitional complex with a QRS of $10 \mathrm{sec}$. was observed.

\section{NOTES OF THE Fourth CASE}

A man, aged 64, was admitted to the Harrogate General Hospital in September 1936 with a history of increasing dyspnœa on exertion for two years and odema for ten weeks. Four years previously his gall-bladder had been removed for severe and gripping pains in the upper abdomen. A partial iridectomy for glaucoma was performed in the same year.

He was cyanosed and orthopnœic with œdema in the legs, scrotum, and lumbo-sacral region. The pulse was 96 . The blood pressure was $156 / 110$. The heart sounds were faint, with an apical gallop rhythm. The heart was greatly enlarged to the left and right, the cardio-thoracic ratio being $19 \mathrm{~cm} . / 33 \mathrm{~cm}$. A tender liver was palpable eight inches below the costal margin. The lungs were congested. The cardiogram showed incomplete A-V block (P-R, $\cdot 24 \mathrm{sec}$.), atypical right branch block $(\mathrm{QRS}, \cdot 12)$ with small deflections in lead $\mathrm{I}$, and right ventricular premature beats (Fig. 20). Under digitalis therapy the heart failure disappeared and he was discharged in three weeks.

In November the blood pressure was 120/68. Fig. 21 shows incomplete

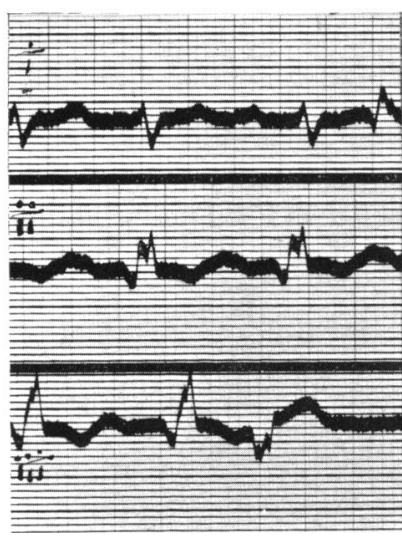

FIG. 20.

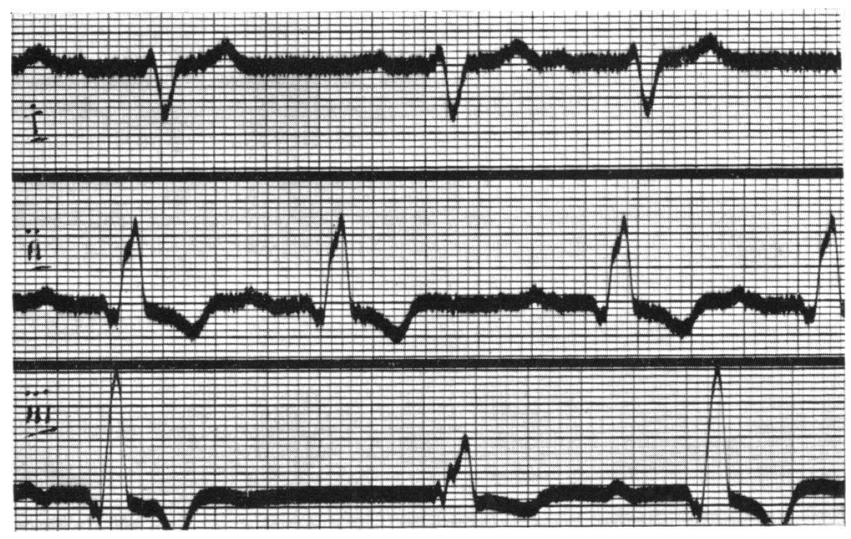

Fig. 21.

FIg. 20.-Case 4. 21,9,36. Incomplete A-V block, (P-R -24 sec.). Right branch block (atypical; QRS, $\cdot 12$ sec.). Right ventricular premature beats.

FIG. 21.-Case 4. 6,11,36. Incomplete A-V block (P-R, $\cdot 24$ sec.). Coupled rhythm probably due to premature auricular beats. Right branch block (type A; QRS, $14 \mathrm{sec}$.). In lead III the second complex is an escape of the ventricle following the failure of an auricular beat. It has a form similar to the atypical right branch block of previous record.

A-V block ( $\mathbf{P}-\mathbf{R} \cdot 24 \mathrm{sec}$.); coupled rhythm probably due to premature auricular beats; right branch block of type A (QRS -14); and a ventricular rate of 68 . In lead III an auricular beat fails, and the escaping ventricular complex returns to the atypical right branch block. In January 1937 auricular fibrillation was present (Fig. 22), with a ventricular rate of 42 to 60 . The right branch block (type A) is unchanged, and in lead II another atypical right branch block 
complex is seen after a long pause. In June 1937 complexes of left branch block $(\mathrm{QRS}, \cdot 12)$ appeared in leads I and III, interspersed with the predominant right branch block of type A (Fig. 23). They resembled the premature beats of Fig. 20. By November 1937 the ventricular rate was regular at 40, auricular fibrillation persisting. The QRS of the right branch block had increased to $\cdot 16$ sec. (Fig. 24).

One morning in June 1938 he had several attacks of unconsciousness and he was admitted to hospital at noon. The pulse was then 36 . From 1 p.m. to 2 p.m. he had eleven Stokes-Adams attacks, for which adrenaline was given. From 5.30 to 6 he had five more and at 11 he died in another. Fig. 25 was taken at

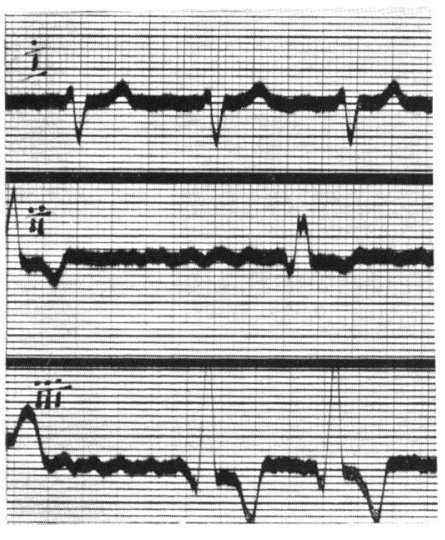

FIG. 22.

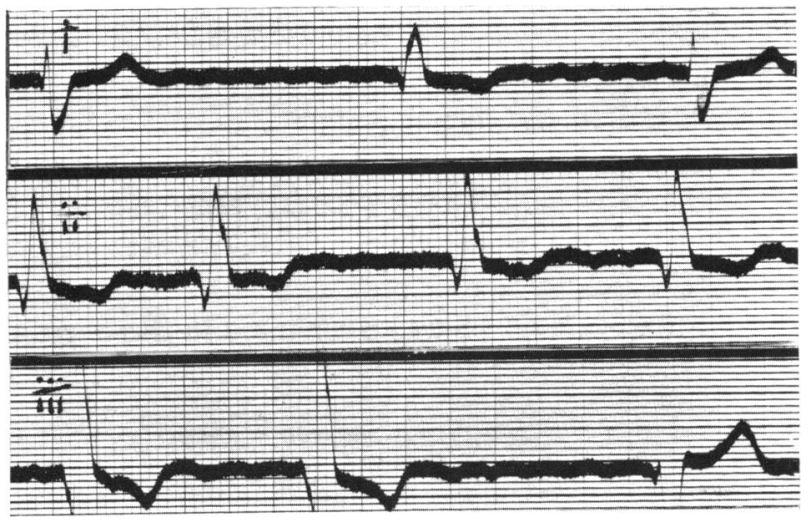

FIG. 23.

FIG. 22-Case 4. 12,1,37. Auricular fibrillation. Right branch block, type A. The second complex in lead II reverts to the atypical right branch block of Fig. 20.

FIG. 23.-Case 4. 1,6,37. Auricular fibrillation. Right branch block, type A. Left branch block seen in leads I and III, similar to the early beats of Fig. 20.

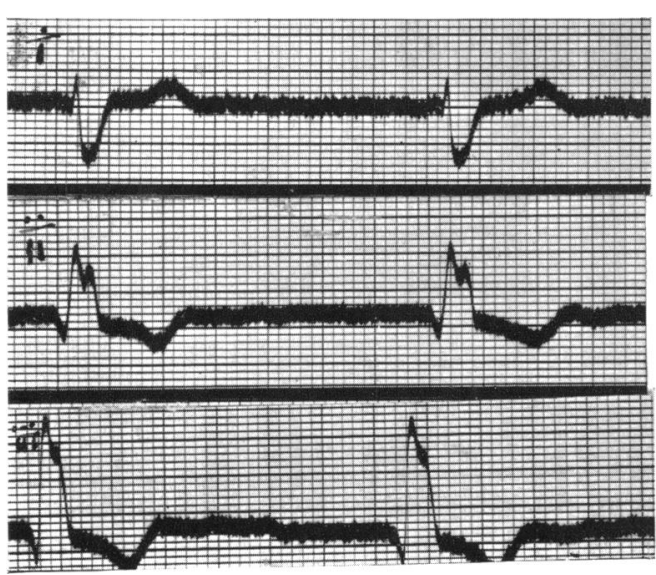

FIG. 24.

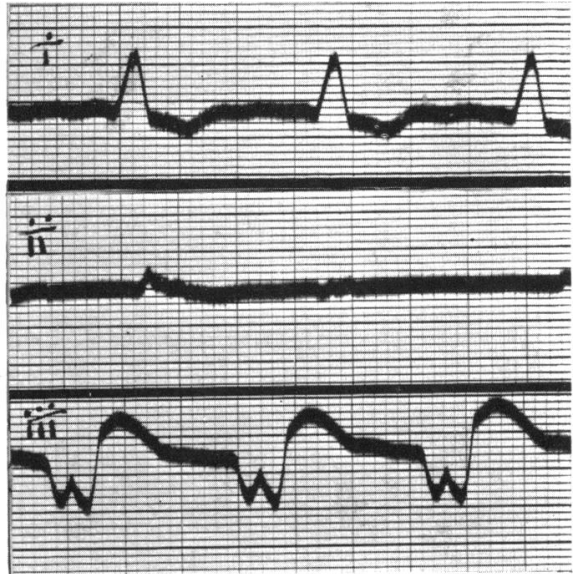

FIG. 25.

FIG 24-Case 4, 14,11,37. Auricular fibrillation and complete A-V block (ventricular rate 40 and regular). Right branch block (QRS, $\cdot 16$ sec.).

FIG. 25.-Case 4. 6,6,38. Left branch block at regular rate of 90 . (QRS, $18 \mathrm{sec}$.). 
$1 \cdot 45$, lead II being exposed during a period of unconsciousness. Leads I and III show a left branch block with a regular rhythm at a rate of 90 , the QRS being $\cdot 18 \mathrm{sec}$.

Summary. - In a man with congestive heart failure, who died from StokesAdams disease, the following changes in the ventricular complexes were observed:

1. Right branch block, atypical $(\mathrm{QRS}, \cdot 12)$ with incomplete $\mathrm{A}-\mathrm{V}$ block (P-R, 24 sec.).

2. Right branch block of type A (QRS, $\cdot 14-16)$ with incomplete A-V block and later auricular fibrillation. Atypical right branch block complexes occurred when the ventricle escaped after the failure of an auricular contraction, and after longer pauses when the auricles were fibrillating.

3. Left branch block complexes (QRS, -12), occurring interspersed with predominant right branch block of type $A$, and resembling the right ventricular premature beats seen in the first record.

4. Left branch block (QRS, 18$)$ at a regular rate of 90 .

\section{Discussion}

Before considering the relation of these curves to bilateral bundle branch block and the evidence in favour of centres in each ventricle as against alternate conduction down each branch it will be advantageous to review the position regarding the width of the QRS.

Duration of the QRS.-Lewis (1925) held that a QRS duration exceeding $\cdot 10$ sec. was sufficient for the diagnosis of bundle branch block, and this view has been adopted by Hunter, Papp, and Parkinson (1940). With an average normal QRS duration of $\cdot 08 \mathrm{sec}$. this allows $.03 \mathrm{sec}$. for the impulse to cross the septum. On the other hand, the Criteria Committee of the New York Heart Association regard $\cdot 13 \mathrm{sec}$. as the minimum figure for a diagnosis of bundle branch block, which agrees with the statement of Ashman and Hull (1937) that it takes .05 or $\cdot 06 \mathrm{sec}$. for the impulse to cross the septum. It has sometimes been assumed that bundle branch block is synonymous with obstruction to the passage of the impulse, but this is not so. As Comeau, Hamilton, and White (1938) state: "So long as the conduction time through the damaged branch is greater than that through the intact branch plus the myocardial pathway between the two ventricles, . . . bundle branch complexes will result." It follows that the duration of the QRS will be in part a measure of the conducting powers of the relatively healthy branch. In bilateral disease with bundle branch complexes the accepted minimum must always be exceeded. Bilateral bundle disease appears to be common: Yater (1938) found some disease in each branch in all of the six cases of bundle branch block that he examined. Moreover, the QRS values in his cases confirm the importance of conduction in the 
relatively healthy branch. Out of three cases of right branch block, two had a QRS of 12 sec.: in each the right branch was destroyed, but in one the left branch was "almost normal," while in the other it was " not interrupted." The third case had a QRS of $\cdot 16 \mathrm{sec}$., and here the right branch was destroyed and the left branch was "almost destroyed." In the three cases of left branch block neither branch was destroyed, so the correlation was less good. Evidence that the impulse may need only $\cdot 03$ or $\cdot 04 \mathrm{sec}$. to cross a septum that is not unduly thick is contained in the study made by Master, Dack, and Jaffe (1938) of bundle branch lesions following coronary occlusions. In two cases (Nos. 4 and 15) a branch block changed after successive occlusions and the QRS increased by $\cdot 03$ or $\cdot 04 \mathrm{sec}$. on each occasion. In one a QRS of $\cdot 10 \mathrm{sec}$. became $.14 \mathrm{sec}$. with left branch block after the second attack, and increased to $\cdot 18 \mathrm{sec}$. with right branch block after the third. In all the cases here recorded the QRS width of some of the ventricular complexes exceeded $\cdot 13$ sec., and it may be that QRS widths of this order signify bilateral conduction defects and that some curves with QRS widths from $\cdot 11$ to $\cdot 13 \mathrm{sec}$. represent a purely unilateral defect. It has, in fact, been recently suggested that chronic bundle branch block usually results from diffuse changes in both branches and that the type of the block is determined by predominant enlargement of one or other ventricle (Master, Kalter, Dack, and Jaffe, 1940).

Bilateral Bundle Branch Block can be diagnosed with confidence when supraventricular impulses pass down each branch alternately, as in Case 2 (Fig. 10). When A-V block is complete the diagnosis is less certain, since it is possible for alternate right and left bundle branch block complexes to be due to the interplay of two ventricular centres, one above a lesion in a branch and the other below it. Thus Fig. 1 (Case 1) might be interpreted as being due to the activity of a centre about the point of division of the bundle, with conduction down the left branch alternating with impulses from a centre below a lesion in the right branch. But it is most unlikely that two ventricular centres would have exactly the same rate, and the characteristic of multiple ventricular centres is the appearance of transitional complexes. In Fig. 1 there are no transitional complexes and the $\mathbf{R}-\mathbf{R}$ intervals are equal, the changes in the branch block complexes having no effect on the regularity of the rhythm. Moreover, the left branch block complexes with a QRS of $\cdot 15 \mathrm{sec}$. ceased after rest and the curve changed to a low voltage curve of right-sided type with a $Q R S$ of $\cdot 11 \mathrm{sec}$, and seven days later, following the injection of adrenaline, the QRS became normal. It would seem that in this patient conduction normally took place down the left branch (R.B.B.B.) activating the ventricle in $\cdot 12$ sec., but in the early stages, by reason of fatigue, this route was not available for the alternate impulses which then passed along the more diseased right branch (L.B.B.B.) reaching the ventricle in $\cdot 15 \mathrm{sec}$. When conduction improved with rest the QRS fell to $\cdot 11 \mathrm{sec}$., and it was restored to normal by adrenaline. The factor of fatigue is also important in Fig. 10, which records the only run of normal rhythm obtained from Case 2, since the first complex shows conduction down the right branch (L.B.B.B.), the second down the left branch (R.B.B.B.) and the third again down the right. 
The curves of Case 3 conform to the experimental records of Wilson and Hermann: who found that, when one branch started to recover after both had been cut, incomplete heart block might occur for a time combined with bundle branch block that was permanent. When first seen complete heart block was starting to lift three weeks after an abrupt onset. The ventricle was being activated from a centre in the right branch (Complete Heart Block and L.B.B.B.), but some supraventricular impulses were coming through at a faster rate with conduction through the left branch (R.B.B.B.) (Fig. 14). One complex showed almost normal conduction, due to the simultaneous activation of both ventricles by the two routes. As recovery proceeded incomplete heart block became established, and then normal rhythm, at first under the influence of atropine, adrenaline, and ephedrine, and later spontaneously; but right bundle branch block persisted. The centre in the right branch produced early beats immediately before normal rhythm was restored by atropine and shortly before it returned spontaneously. The rhythm during the final phase of complete heart block with Stokes-Adams attacks was furnished by a second centre which was probably lower down in the right branch since the complexes resembled the premature beats induced by adrenaline.

In Case 4 incomplete heart block ( $\mathrm{P}-\mathrm{R}, \cdot 24 \mathrm{sec}$.) was present in the early records. Later the auricles fibrillated, but it is probable that complete dissociation was present when the ventricular rate became regular at 40 (Fig. 24). Conduction through the ventricle was down the left branch (R.B.B.B.) with a gradual increase in the QRS from $\cdot 12$ to $\cdot 16 \mathrm{sec}$; but a centre in the right branch was responsible first for early beats (Fig. 20) and later for escapes of the ventricle following longer pauses during auricular fibrillation (Fig. 23). All these complexes had the same form and a QRS of $\cdot 12 \mathrm{sec}$. The final curve (Fig. 25) shows conduction through the right branch, or from a centre in it, at a rate of 90 with a QRS of $18 \mathrm{sec}$. In a similar case, Comeau, Hamilton, and White (1938) attributed the new rhythm to irritation of an impulse-forming centre in the diseased branch; but in their case the QRS decreased from $\cdot 16$ to $\cdot 14 \mathrm{sec}$. with the change in the branch block instead of increasing as here from $\cdot 16$ to $\cdot 18 \mathrm{sec}$. Moreover, the centre previously active in the right branch had hitherto shown a constant QRS of $\cdot 12 \mathrm{sec}$. It is possible that the quickened rate might be associated with a wider QRS, but it is much more likely that the gradual increase in the QRS of the right branch block complexes was due to increasing difficulty of conduction in the less damaged left branch, and that in the last phase fresh damage in that branch made it necessary for the impulse to travel through the right branch, which had hitherto provided the slower route.

Multiple Impulse-forming Centres in the Ventricle.-In Cases 1 and 2, A-V block was always complete, except for a short time in Case 2. Both, however, showed evidence of retrograde conduction from ventricle to auricle when the time relations with the preceding $P$ waves were favourable, and the $\mathbf{R}-\mathbf{P}$ interval was $\cdot 16$ to $\cdot 18 \mathrm{sec}$. It cannot be supposed that an impulse generated below a lesion in a branch sufficiently dense to cause complete forward block could penetrate that lesion, traverse the main bundle, pass through the node and 
activate the auricle in $\cdot 16 \mathrm{sec}$. The variable branch block complexes in these cases cannot, therefore, be explained by postulating ventricular centres below lesions in the branches. Moreover, in Case 2 the complexes did not alter during the phase of incomplete $\mathrm{A}-\mathrm{V}$ block when the ventricles were responding to supraventricular impulses. However, in this patient conduction through the left branch (R.B.B.B.) changed after a spell of dizziness to conduction through the right branch (L.B.B.B.) at a slower rate, and the rate with conduction through the right branch was always rather slower during complete A-V block than with conduction through the left, except once after atropine. Many transitional complexes were also observed. Most of these were minor alterations in shape affecting chiefly the right branch block complexes (Fig. 9, lead II), but an intermediate complex is seen in Fig. 12 which shows transition from left to right branch block. The evidence suggests that two ventricular centres were active, while complete A-V block was present, but that both were above the lesions in the branches. In Case 3 transitional complexes, one with an almost normal QRS, point to a ventricular centre in the right branch in addition to the supra-ventricular impulses which passed along the left branch; and another centre in the right branch was responsible for the rhythm during the last phase. Case 4, too, had a second impulse-forming centre in the right ventricle which produced premature beats, and later, escapes of the ventricle. These three patients all died from Stokes-Adams disease.

In Case 1 there was no evidence of a second ventricular centre. No transitional complexes were seen, no variations in speed between the right and left branch block complexes, and no premature beats. It is difficult to avoid the conclusion that in this case a single centre above the point of division of the bundle was responsible for all the complexes observed with variable conduction down each branch. This patient had no Stokes-Adams attacks.

Curves of Incomplete Bundle Branch Block.-The increase in the QRS of the right branch block complexes in Case 4 was associated with a change in their form. The early curves with a QRS of $\cdot 12$ sec. had small deflections, especially in lead I; the later curves were of the classical type A right branch block. There can be little doubt that the first type represent a less complete form of right branch block, since they reappeared as escapes of the ventricle on those occasions when the conducting tissue had more time in which to recover owing to the failure of an auricular contraction (Fig. 21). The right branch block curves of Case 2 (QRS, -14) similarly had small deflections in lead I, and they changed to right branch block of type A after adrenaline. The fibre was under continuous observation from the time of the injection and no cessation of ventricular activity was seen. The rate of the type A complexes in lead I was 27, which is less than the rate before injection. The complexes appeared to be due rather to a change in the path of the impulse than to the activity of a new centre.

It has been suggested that curves with a QRS width between $\cdot 10$ and $\cdot 12$ sec. should be interpreted as incomplete bundle branch block, but with bilateral disease the width of the QRS can bear only a limited relationship to the completeness of the bundle branch block. Lewis (1925) was of the opinion that 
delay in conduction down one branch could modify considerably the form of the cardiogram, and it is probable that some of the atypical forms recently interpreted as right branch block may in reality signify incomplete bundle branch block, the widened QRS being due to bilateral disease.

\section{SummaRY AND CONCLUSIONS}

Four cases of A-V heart block with varying ventricular complexes have been observed. In two the A-V block was nearly always complete, although retrograde conduction occurred at times from ventricle to auricle; in the other two the A-V block varied. Analysis of the curves obtained suggests that bilateral bundle conduction defects were present in all of these cases. In three the evidence pointed to multiple centres of impulse formation, and these all died from Stokes-Adams disease; in one it was concluded that variable conduction was taking place down each branch from a single idio-ventricular centre, and he has had no Stokes-Adams attacks.

1. Varying ventricular complexes in A-V heart block usually signify the presence of bilateral bundle conduction defects.

2. The impulses may arise from one or more places in the ventricles. Multiple foci of origin increase considerably the risk of Stokes-Adams attacks.

3. The duration of the QRS in bundle branch block is in part a measure of the speed of conduction in the relatively healthy branch: in bilateral bundle lesions the accepted minimum must always be exceeded. In those cases in which one branch is conducting normally, this minimum width may not exceed $\cdot 11 \mathrm{sec}$.

4. Some forms of atypical right branch block may represent incomplete right branch block, the wide QRS being due to the presence of bilateral defects.

\section{REFERENCES}

Ashman and Hull (1937). Essentials of Electrocardiography, p. 46.

Coelho, E. (1932). Arch. Mal. Couur., 25, 695.

Cohn, A. E. (1913). Heart, 5, 5.

and Lewis, T. (1912). Ibid., 4, 15.

Comeau, W. J., Hamilton, J. G. M., and White, P. D. (1938). Amer. Heart J., 15, 276.

Don, C. S. D., Grant, R. T. and Camp, P. D. (1932). Heart, 16, 145.

Faulkner, J. M. (1932). Med. Clin. N. Amer., 15, 998.

Gilchrist, A. R., and Cohn, A. E. (1928). Amer. Heart J., 3, 146.

Hunter, A., Papp, C., and Parkinson, J. (1940). Brit. Heart J., 2, 107

King, J. T. (1934). Amer. J. Med. Sci., 187, 149.

Lewis, T. (1925). Mechanism and Graphic Registration of Heart Beat, pp. 45, 133.

Master, M. A., Dack, S., and Jaffe, H. L. (1938). Amer. Heart J., 16, 283.

— Kalter, H., Dack, S., and Jaffe, H. L. (1940). Ibid., 20, 186.

H 
Mathewson, G. D. (1913). Heart, 4, 385.

New York Heart Association (1939). Criteria for Diagnosis of Diseases of the Heart, p. 132.

Scherf, D. and Schott, A. (1932). Klin. Wschr., 11, 945.

Willius, F. A. (1924). Ann. Clin. Med., 3, 129.

Wilson, F. N. and Hermann, G. R. (1921). Heart, 8, 229.

Yater, W. M. (1938). Arch. intern. Med., 62, 1.

Cornell, V. H. and Clayton, T. (1936). Ibid., 57, 132. 